\title{
Induced Pluripotent Stem
} Cell-Derived Brain Endothelial Cells as a Cellular Model to Study Neisseria meningitidis Infection

\section{OPEN ACCESS}

Edited by:

Sven Hammerschmidt,

University of Greifswald, Germany

Reviewed by:

Christian Schwerk, University Hospital Heidelberg,

Germany

Evgeny A. Semchenko, Griffith University, Australia

${ }^{*}$ Correspondence:

Brandon J. Kim

brandon.kim@

hygiene.uni-wuerzburg.de

Antje Appelt-Menzel

antje.appelt-menze/@

uni-wuerzburg.de

Alexandra Schubert-Unkmeir aunkmeir@hygiene.uni-wuerzburg.de

${ }^{t}$ These authors have contributed equally to this work

Specialty section: This article was submitted to

Infectious Diseases,

a section of the journal

Frontiers in Microbiology

Received: 25 March 2019 Accepted: 09 May 2019

Published: 29 May 2019

Citation:

Martins Gomes SF,

Westermann AJ, Sauerwein T, Hertlein T, Förstner KU, Ohlsen K, Metzger M, Shusta EV, Kim BJ,

Appelt-Menzel A and

Schubert-Unkmeir A (2019) Induced Pluripotent Stem Cell-Derived Brain Endothelial Cells as a Cellular Model

to Study Neisseria meningitidis Infection. Front. Microbiol. 10:1181. doi: 10.3389/fmicb.2019.01181
Sara F. Martins Gomes ${ }^{1}$, Alexander J. Westermann" ${ }^{2,3}$, Till Sauerwein ${ }^{2,4,5}$, Tobias Hertlein ${ }^{2}$, Konrad U. Förstner $2,4,5$, Knut Oh/sen ${ }^{2}$, Marco Metzger ${ }^{6,7}$, Eric V. Shusta ${ }^{8}$, Brandon J. Kim ${ }^{1,8 *}$, Antje Appelt-Menzel/6,7*t and Alexandra Schubert-Unkmeir ${ }^{1 * \dagger}$

${ }^{1}$ Institute of Hygiene and Microbiology, University of Würzburg, Würzburg, Germany, ${ }^{2}$ Institute of Molecular Infection Biology (IMIB), University of Würzburg, Würzburg, Germany, ${ }^{3}$ Helmholtz Institute for RNA-based Infection Research (HIRI), Helmholtz Centre for Infection Research (HZI), Würzburg, Germany, ${ }^{4}$ ZB MED, Information Centre for Life Sciences, Cologne, Germany, ${ }^{5}$ TH Köln, University of Applied Sciences, Faculty of Information Science and Communication Studies, Cologne, Germany, ${ }^{6}$ Chair Tissue Engineering and Regenerative Medicine, University Hospital Würzburg, Würzburg, Germany,

${ }^{7}$ Fraunhofer Institute for Silicate Research ISC, Translational Center Regenerative Therapies (TLC-RT), Würzburg, Germany,

${ }^{8}$ Department of Chemical and Biological Engineering, University of Wisconsin-Madison, Madison, WI, United States

Meningococcal meningitis is a severe central nervous system infection that occurs when Neisseria meningitidis ( $\mathrm{Nm}$ ) penetrates brain endothelial cells (BECs) of the meningeal blood-cerebrospinal fluid barrier. As a human-specific pathogen, in vivo models are greatly limited and pose a significant challenge. In vitro cell models have been developed, however, most lack critical BEC phenotypes limiting their usefulness. Human BECs generated from induced pluripotent stem cells (iPSCs) retain BEC properties and offer the prospect of modeling the human-specific $N m$ interaction with BECs. Here, we exploit iPSC-BECs as a novel cellular model to study $\mathrm{Nm}$ host-pathogen interactions, and provide an overview of host responses to Nm infection. Using iPSC-BECs, we first confirmed that multiple $\mathrm{Nm}$ strains and mutants follow similar phenotypes to previously described models. The recruitment of the recently published pilus adhesin receptor CD147 underneath meningococcal microcolonies could be verified in iPSC-BECs. $\mathrm{Nm}$ was also observed to significantly increase the expression of pro-inflammatory and neutrophil-specific chemokines IL6, CXCL1, CXCL2, CXCL8, and CCL20, and the secretion of IFN- $\gamma$ and RANTES. For the first time, we directly observe that $\mathrm{Nm}$ disrupts the three tight junction proteins ZO-1, Occludin, and Claudin-5, which become frayed and/or discontinuous in BECs upon $\mathrm{Nm}$ challenge. In accordance with tight junction loss, a sharp loss in trans-endothelial electrical resistance, and an increase in sodium fluorescein permeability and in bacterial transmigration, was observed. Finally, we established RNA-Seq of sorted, infected iPSC-BECs, providing expression data of $\mathrm{Nm}$-responsive host genes. Altogether, this model provides novel insights into $\mathrm{Nm}$ pathogenesis, including an impact of $\mathrm{Nm}$ on barrier properties and tight junction complexes, and suggests that the paracellular route may contribute to $\mathrm{Nm}$ traversal of BECs.

Keywords: Neisseria meningitidis, meningococcus, bacteria, stem cells, blood-cerebrospinal fluid barrier, bloodbrain barrier, brain endothelial cells 


\section{INTRODUCTION}

Neisseria meningitidis or meningococcus $(\mathrm{Nm})$ is a Gramnegative human-exclusive pathogen that asymptomatically colonizes the upper respiratory tract of $10-40 \%$ of the world population (Rouphael and Stephens, 2012). In susceptible individuals, $\mathrm{Nm}$ infection is a leading cause of purpura fulminans and meningitis. Meningitis is a disease that is still associated with high mortality despite administration of modern antibiotic therapy (Rouphael and Stephens, 2012). Invasive meningococcal disease initiates when $\mathrm{Nm}$ crosses the epithelium of the nasopharynx and reaches the bloodstream, where it is able to resist complement-mediated killing and proliferate (Quagliarello and Scheld, 1992). Binding of $\mathrm{Nm}$ to the endothelium of brain microvessels that compose the meningeal blood-cerebrospinal fluid barrier (b-CSF) and blood-brain barrier (BBB) is a crucial step in disease progression (Mairey et al., 2006; Weller et al., 2018). Binding of type IV pili to host receptor CD147 triggers the formation of highly ordered CD147//2-adrenergic receptor clusters assembled by the scaffolding protein $\alpha$-actinin- 4 (Maïssa et al., 2017). The activation of this receptor promotes the recruitment of the polarity complex to the bacterial adhesion site together with adherens and tight junction proteins, leading to the opening of a paracellular route that may facilitate bacterial passage (Coureuil et al., 2009; Bernard et al., 2014). Previous work has demonstrated that $N m$ is internalized by endothelial cells in membrane-bound compartments referred to as Neisseriacontaining vacuoles, presumed to offer a protective niche for intracellular multiplication and potentially serve as a vehicle for transcytosis (Nikulin et al., 2006). Therefore, the primary transit route of BECs by $\mathrm{Nm}$ has yet to be determined, highlighting the need for further investigation.

Though initial host-pathogen contact is thought to be type IV pili-dependent, the interaction and invasion of the b-CSF barrier is greatly supported by other virulence factors such as colony opacity associated proteins Opa and OpcA (Virji et al., 1993), and recently identified minor adhesion and adhesionlike proteins [reviewed in Hung and Christodoulides (2013)]. Previous studies using an immortalized line of human brain microvascular endothelial cells (HBMECs) also reported that $\mathrm{Nm}$ infection induces the release of pro-inflammatory cytokines involved in neutrophil and monocyte recruitment (Sokolova et al., 2004; Dick et al., 2017).

The b-CSF barrier is one of five main interfaces identified in the adult brain and BECs are presumed to be the first obstacle that meningococci must breach in order to reach the leptomeninges (Weller et al., 2018). BECs are highly specialized cells that maintain cerebral homeostasis and protect the brain from toxic compounds and pathogens (van Sorge and Doran, 2012; Weller et al., 2018). BECs accomplish this through their selectively permeable and barrier-forming phenotype, that arises from the presence of complex tight junctions, efflux transporters and highly regulated receptormediated transcytosis (Engelhardt and Sorokin, 2009). Studies with immortalized HBMECs and other endothelial cell lines have elucidated many of the known Nm-BEC interactions (SchubertUnkmeir, 2017). However, immortalized cell lines do not retain important phenotypes of BECs such as strong barrier properties, namely high trans-endothelial electrical resistance (TEER), responsiveness to other cell types of the neurovascular unit, and expression of important tight junction markers (Weksler et al., 2005; Eigenmann et al., 2013).

Advances in human stem cell technologies have provided the prospect of utilizing highly scalable human systems to model specific cell types such as BECs (Lippmann et al., 2012). BECs generated from induced pluripotent stem cells (iPSC) exhibit advantages over current in vitro models of BECs as they retain expected brain phenotypes and functional features while also being of human origin. In addition, iPSC-BECs possess significant barrier properties, reaching TEER values over $2500 \Omega \times \mathrm{cm}^{2}$ (Lippmann et al., 2014). Finally, iPSC-BECs have been shown to respond to other cell types of the neurovascular unit that help regulate barrier function (Lippmann et al., 2012, 2014; Appelt-Menzel et al., 2017; Canfield et al., 2017).

The human specificity of $\mathrm{Nm}$ and the lack of robust BEC phenotypes in presently utilized models emphasize the need for new models possessing properties more consistent with BECs in vivo. Here, we demonstrate the usefulness of iPSCBECs in vitro to study $\mathrm{Nm}$ infection. Additionally, we profiled host expression patterns in response to $\mathrm{Nm}$ infection by specifically selecting invaded iPSC-BECs and sequencing their transcriptome. Altogether, this model provides novel insights into $\mathrm{Nm}$ pathogenesis, including an impact of $\mathrm{Nm}$ on barrier properties and tight junction complexes, and suggests that the paracellular route may contribute to $\mathrm{Nm}$ traversal of BECs.

\section{RESULTS}

\section{Nm Interacts With iPSC-Derived BECs}

To investigate whether $\mathrm{Nm}$ interacts with iPSC-BECs, iPSCs were differentiated to BECs according to previously published methods (Lippmann et al., 2012, 2014; Stebbins et al., 2016; Appelt-Menzel et al., 2017). We observed expected barrier properties as measured by high TEER and marker expression, such as CD31 and Glut-1, as previously described (Stebbins et al., 2016; Supplementary Figure 1). Monolayers were infected with two wild-type (WT) and two mutant $\mathrm{Nm}$ strains all expressing a variety of characterized virulence factors (Figure 1A). Gentamicin protection assays were used to estimate the relative invasion of $\mathrm{Nm}$ into iPSC-BECs. Capsule-deficient MC58 $\Delta$ siaD was observed to be more invasive than its WT strain, and levels were consistent to previous reports with immortalized BECs, where no differences between growth curves were observed (Unkmeir et al., 2002; Johswich et al., 2013; Figure 1B). Similar patterns were observed by confocal microscopy, where MC58 $\Delta$ siaD was relatively more abundant compared with the parent WT strain (Figure 1C). Previous work with immortalized cells have demonstrated the importance of the pilus in mediating bacterial invasion into host BECs (Hoffmann et al., 2001). Although no significant difference in invasion could be observed in a pilus-deficient $\Delta p i l E$ mutant (Supplementary Figure 2B), we found that the pilusoverexpressing $\Delta$ pilT mutant is hyper invasive in iPSC-BECs 

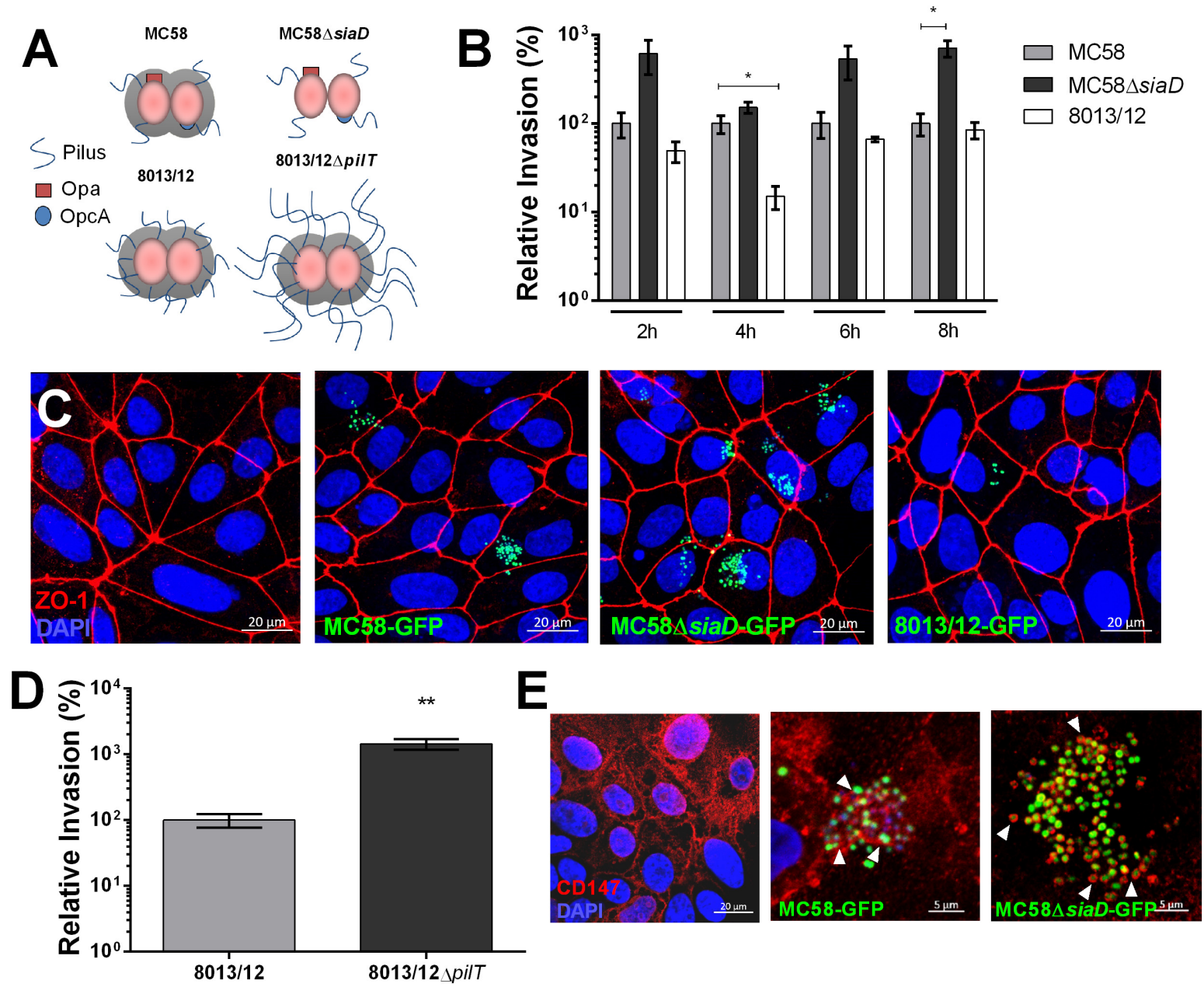

FIGURE 1 | Characterization of Nm interaction with iPSC-BECs. (A) Schematic cartoon of Nm strains used. MC58 is a serogroup B strain, MC58 $\Delta$ siaD is an isogenic non-capsulated mutant, 8013/12 is a serogroup C strain and 8013/12 $\Delta$ pilT is a highly piliated mutant. (B) Gentamicin protection assay of $N m$ on iPSC-BECs showing invasion of MC58 $\triangle$ siaD and 8013/12 relative to MC58 into iPSC-BECs at the indicated time points and Multiplicity of Infection (MOI) of 10. (C) Confocal microscopy images of iPSC-BECs infected with the Nm strains mentioned in (B), at $4 \mathrm{~h} \mathrm{p.i.} \mathrm{and} \mathrm{MOI} \mathrm{100.} \mathrm{Image} \mathrm{is} \mathrm{a} \mathrm{maximum} \mathrm{image} \mathrm{projection.} \mathrm{Scale}$ bar $=20 \mu \mathrm{m}$. (D) Gentamicin protection assay showing invasion of $\Delta$ pilT mutant relative to WT 8013/12 Nm strains into iPSC-BECs at $4 \mathrm{~h}$ p.i. and MOI 10. For (B,D) data is presented as mean \pm S.E.M of three independent experiments done in technical duplicate and triplicate, respectively. Student's $t$-test was used to determine significance. ${ }^{*} p<0.05 ; * * p<0.01$. (E) Immunofluorescence staining showing areas of recruitment of receptor CD147 (red) around MC58 and MC58 $\Delta$ siaD colonies (green) highlighted with white arrow heads in iPSC-BECs at $4 \mathrm{~h}$ p.i. and MOI of 100 . Scale bar $=5 \mu \mathrm{m}$.

compared to invasion rates of the WT strain, suggesting a role for the pilus during infection (Figure 1D). Absolute values of invasion of these strains are shown in Supplementary Figure 2, as well as the respective growth curves. Binding of type IV pilus to BECs is hypothesized to be a critical aspect of $\mathrm{Nm}$ infection preceding the translocation of the b-CSF barrier (Coureuil et al., 2012). CD147 was recently described as the type IV pilus receptor in a study conducted with immortalized endothelial cells (Bernard et al., 2014). Immunofluorescence staining of CD147 during infection with GFP-expressing MC58 and MC58 $\Delta$ siaD strains shows close proximity of this receptor at sites of bacterial attachment similar to the previous report (Bernard et al., 2014; Figure 1E). Taken together, these results demonstrate that various strains and mutants of $\mathrm{Nm}$ can interact with iPSC-BECs following similar patterns and phenotypes to previously described models, and that iPSC-BECs possess an important receptor for virulence.

\section{$\mathrm{Nm}$ Infection Leads to Barrier Permeability}

To assess if $\mathrm{Nm}$ challenge impacts barrier integrity of iPSCBECs, the TEER profile of mock and infected monolayers was measured over time. At $24 \mathrm{~h}$ a trend for decreasing TEER could be observed in infected transwells, which became significant at $28 \mathrm{~h}$ (Figure 2A). At $32 \mathrm{~h}$ TEERs of infected monolayers dropped $90 \%$ when compared to controls, suggesting that $\mathrm{Nm}$ causes barrier disruption at late infection time points. To further establish that $\mathrm{Nm}$ infection impairs barrier function, paracellular permeability to sodium fluorescein $(\mathrm{NaF})$ was quantified (Stebbins et al., 2016). In support of 

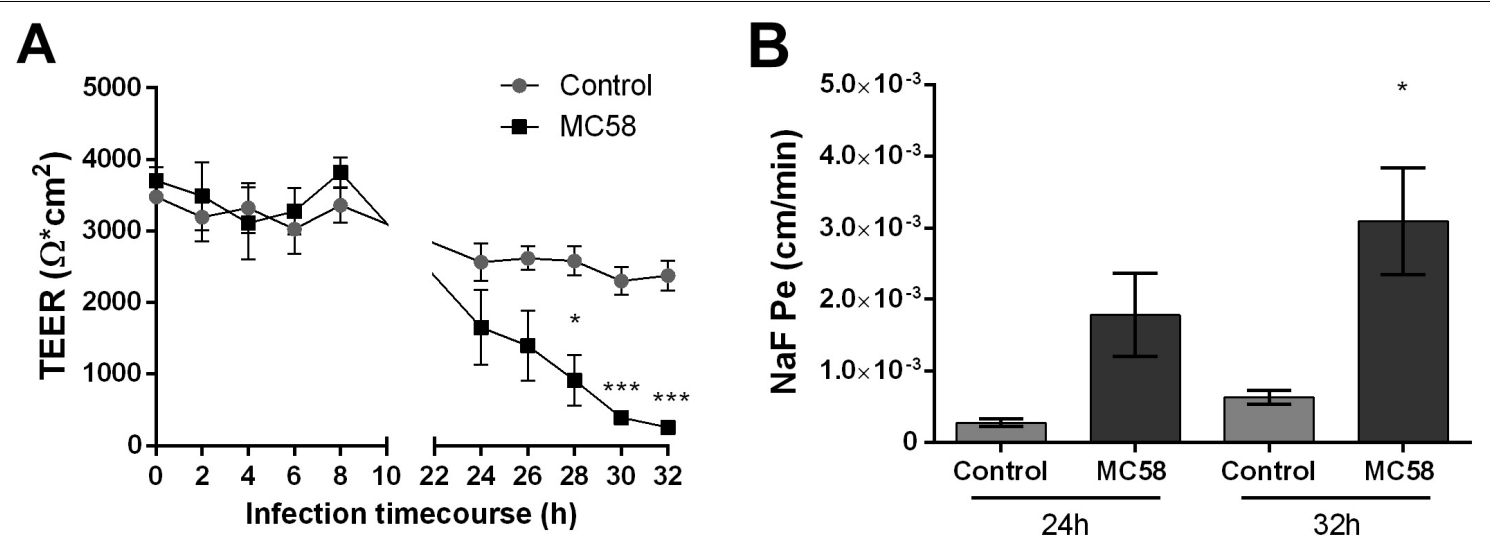

FIGURE 2 | Neisseria meningitidis infection impacts barrier properties of iPSC-BECs. (A,B) iPSC-BEC monolayers seeded onto $0.4 \mu \mathrm{m}$ pore size transwells with or without $\mathrm{Nm}$ challenge at $\mathrm{MOI} 10$ were used for $(\mathbf{A})$ monitoring of TEER values $\left(\Omega \times \mathrm{cm}^{2}\right)$ over a time course of $32 \mathrm{~h}$ and $(\mathbf{B})$ determination of NaF permeability coefficient $(\mathrm{cm} / \mathrm{min})$ at 24 and $32 \mathrm{~h}$ p.i. The data are represented as mean \pm S.E.M. of three independent experiments each done in technical triplicate. Student's t-test was used to determine significance. * $p<0.05 ;{ }^{* * *} p<0.001$.

the TEER dynamics, an increase in NaF permeability was observed at $24 \mathrm{~h}$, which became significant at $32 \mathrm{~h}$ (4.9fold higher for infected cells when compared to controls) (Figure 2B). These data suggest that $\mathrm{Nm}$ infection impairs barrier function of iPSC-BEC monolayers by increasing barrier permeability.

\section{$\mathrm{Nm}$ Infection Results in Tight Junction Disruption}

To observe if there are changes in host tight junctions during infection, immunostaining for tight junction components ZO1, Occludin, and Claudin-5 was conducted. No changes in the levels and localization of tight junction proteins could be detected at $8 \mathrm{~h}$ and $16 \mathrm{~h}$ p.i. (Supplementary Figures 3A,B). However, at $24 \mathrm{~h}$ p.i. gaps between cells and frayed junctions were observed. Junction discontinuity could be observed for Occludin and Claudin-5 but not ZO-1, however, ZO-1 appeared to be frayed (Figure 3A). No changes in protein content occurred at early time points, however, a trend for a decrease of ZO-1, Occludin, and Claudin-5, could be observed at $32 \mathrm{~h}$ of infection (Supplementary Figure 3C). Interestingly, an additional band at lower molecular weight was observed for Occludin, which may correspond to a cleavage product generated upon $\mathrm{Nm}$ infection, as previously described in immortalized HBMECs (Supplementary Figure 3C; Schubert-Unkmeir et al., 2010). A higher molecular weight band for Occludin could be observed at 24 and $32 \mathrm{~h}$ p.i., possibly corresponding to post-translational modifications (Ni et al., 2017). Consistent with the protein data, regulation of tight junction expression at the mRNA level in infected monolayers was not observed at $8 \mathrm{~h}$ p.i., whereas at $24 \mathrm{~h}$ TJP1 and CLDN5 expression significantly decreased (Figure 3B). Previous work suggests that bacteria can disrupt tight junctions in BECs through the upregulation of host Snail-1 (SNAI1), a transcriptional repressor of tight junction components (Kim et al., 2015, 2017; Yang et al., 2016). To assess if this transcription factor is upregulated during $\mathrm{Nm}$ infection, qPCR for SNAI1 was conducted. We observed that upregulation of SNAI1 occurs as early as $4 \mathrm{~h}$ p.i. in infected cultures, although it is notably higher at later time points (Figure 3C). Taken together, these findings suggest that tight junctions are disrupted in BECs during $\mathrm{Nm}$ infection.

To determine if the observed junctional disruption contributes to $\mathrm{Nm}$ crossing through iPSC-BECs, transmigration studies were carried out. Bacteria could not be detected in the basolateral chamber of infected transwells before $6 \mathrm{~h}$ of infection, and remained below the detection limit of the assay at 6 and $8 \mathrm{~h}$. At $24 \mathrm{~h}$, the number of CFUs crossing the monolayer drastically increased when compared to $8 \mathrm{~h}$ of infection (Figure 3D). Together, these results demonstrate that $\mathrm{Nm}$ causes tight junction disruption of iPSC-BECs possibly through upregulation of host SNAI1. Nm-induced tight junction re-arrangements coincide with a dramatic increase in $\mathrm{Nm}$ traversal through the endothelial barrier.

\section{Nm Infection Activates iPSC-BECs}

Meningitis disease progression is characterized by the inflammation of the meninges, presumed to be provoked by BECs (Tunkel and Scheld, 1993). To investigate whether iPSC-BECs are activated upon $N m$ infection, a panel of 14 cytokines/chemokines was selected for Luminex bead-based multiplex assays. Our results show that RANTES and IFN- $\gamma$ are significantly more abundant in the supernatants after 8 and $24 \mathrm{~h}$ of $\mathrm{Nm}$ infection (Figure 4A). Although a statistically significant increase in IL-8 levels in supernatants derived from infected monolayers was observed at $24 \mathrm{~h}$ p.i., it should be noted that the magnitude of secretion $(8 \mathrm{pg} / \mathrm{mL})$ is very low compared with other cell types (Dick et al., 2017; Figure 4A). Similar trends were observed for supernatants collected from monolayers infected with $N m$ strains MC58 $\Delta$ siaD and 8013/12 (Supplementary Figure 4A). qPCR on RNA from infected cultures confirmed upregulation of CCL5 (RANTES) and IFNG (INF- $\gamma$ ) at $24 \mathrm{~h}$ p.i. (Supplementary Figure 4B). No detection or detection below the standard limit was observed for IL-6, IL-1 $\beta$, Gro- $\alpha$, GM-CSF, 


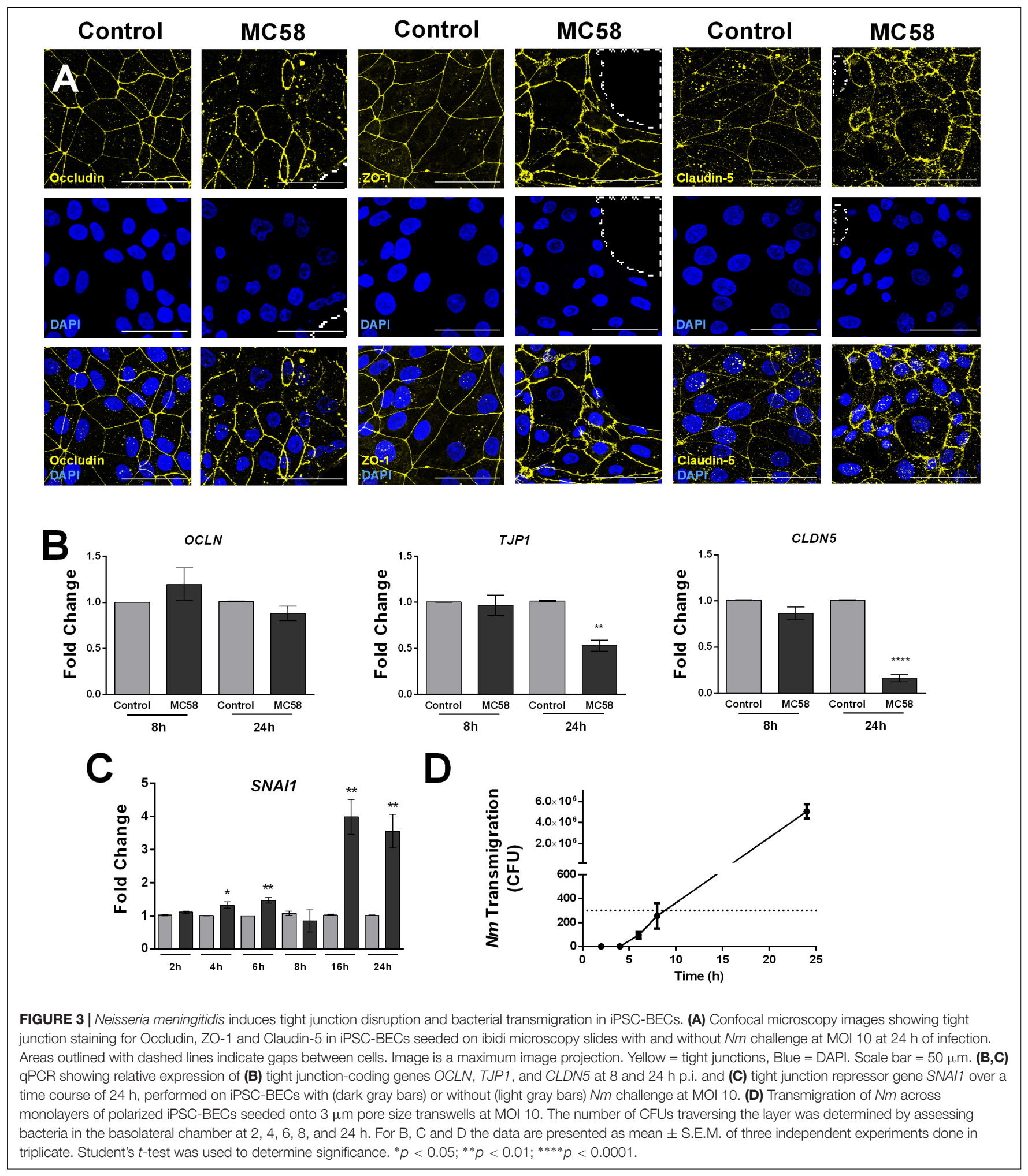

TNF- $\alpha$, ICAM-1, and vWF-A2 (data not shown). No difference between control versus MC58 was observed for VCAM-1, E-Selectin, and Gro- $\beta$ (Supplementary Figure 4C). In contrast, time-dependent increase of IL- 6 and IL- 8 could be detected for immortalized HBMECs infected with MC58 and MC58 4 siaD (Supplementary Figure 4D), as described previously (Dick et al., 2017). Activation of iPSC-BECs in response to $\mathrm{Nm}$ infection was further assessed with qPCR of neutrophilic chemoattractants 


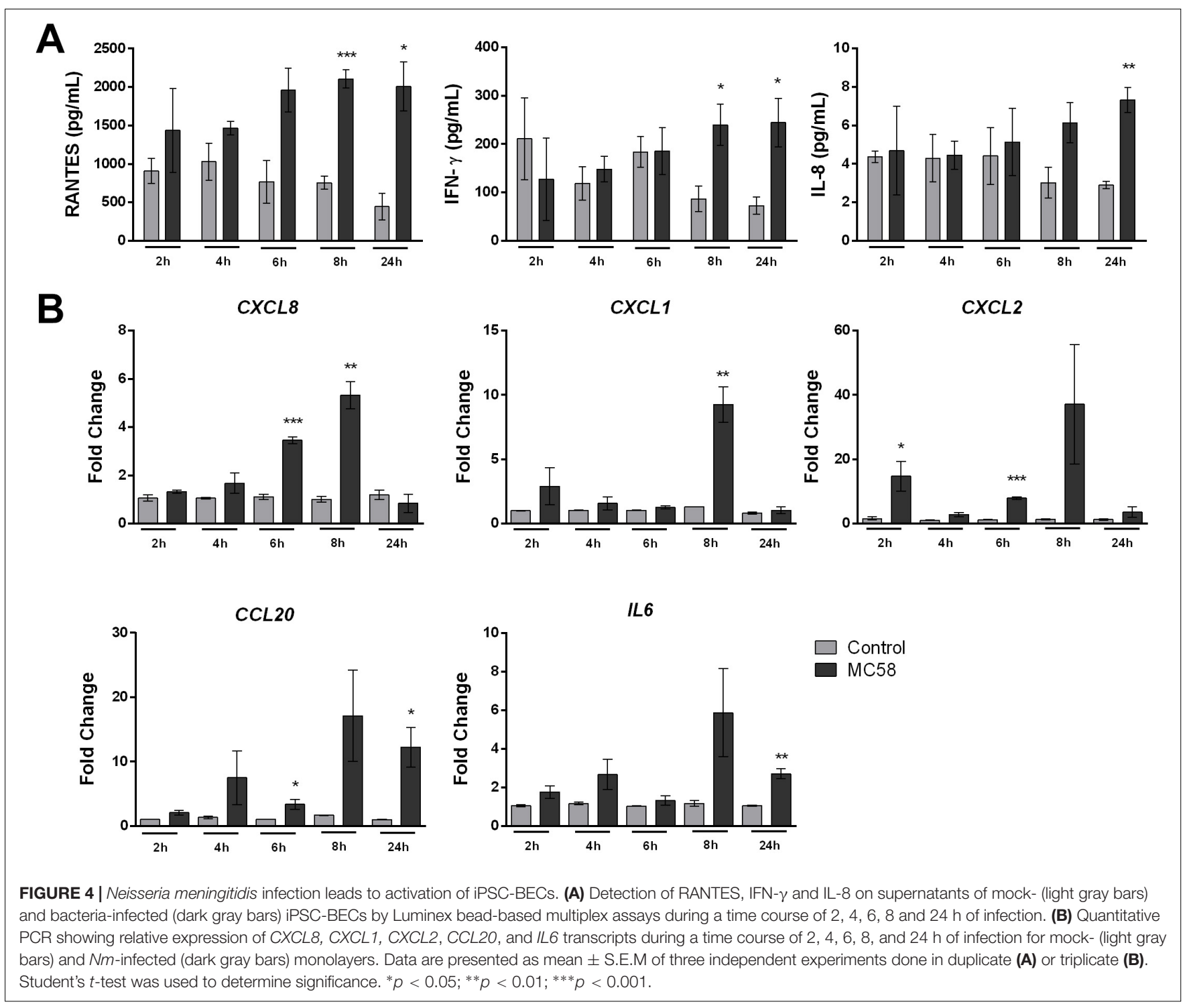

and activators CXCL8, CXCL1, CXCL2, CCL20, and IL6 gene expression. Our results show that these important neutrophilic factors are upregulated during the time course of infection (Figure 4B). Overall, our data suggest that iPSC-BECs can sense and respond to bacteria and are activated upon $\mathrm{Nm}$ challenge through the upregulation of some pro-inflammatory factors.

\section{RNA-Seq of $\mathbf{N m}$-Infected iPSC-BECs}

Above, we characterized the response of bulk cultures of $\mathrm{Nm}$ challenged iPSC-BECs, i.e., without discriminating between invaded and non-invaded, bystander cells. To specifically track transcriptomic changes originated by the population of invaded host cells, we enriched infected (GFP-positive) from non-infected (GFP-negative) iPSC-BECs at $24 \mathrm{~h}$ of $\mathrm{Nm}$ infection using fluorescence-activated cell sorting (FACS) as previously described (Westermann et al., 2016; Figure 5A and Supplementary Figure 5A). From the collected $\mathrm{Nm}$-invaded cell population, we isolated total RNA and converted the polyadenylated transcripts (i.e., human mRNAs and polyadenylated long non-coding RNAs) into cDNA libraries. RNA-Seq analysis led to the identification of a total of 100 differentially expressed genes [61 mRNAs and 39 non-coding RNAs (ncRNAs), Figure 5B and Supplementary Figure 5B] as compared to mock-treated control cells. Of the 61 mRNAs, 22 were downregulated while 39 were upregulated relative to the uninfected control. Interestingly, while several of the upregulated mRNAs (e.g., TNFAIP2, BCL3) were previously reported as Nm-induced host transcripts in a human blood-cerebrospinal fluid barrier model by microarray analysis (Borkowski et al., 2014), others had not been identified in this previous screen. Gene Ontology (GO) analysis of the induced mRNAs using DAVID (Huang et al., 2009) yielded significantly enriched $(P$-value $<0.05)$ GO terms, generally related to cellular stress and hypoxia (Figure 5C). We sought to validate some of these results through independent qPCR on RNA samples from bulk (unsorted) cultures. Specifically, the mRNA encoding vascular endothelial 

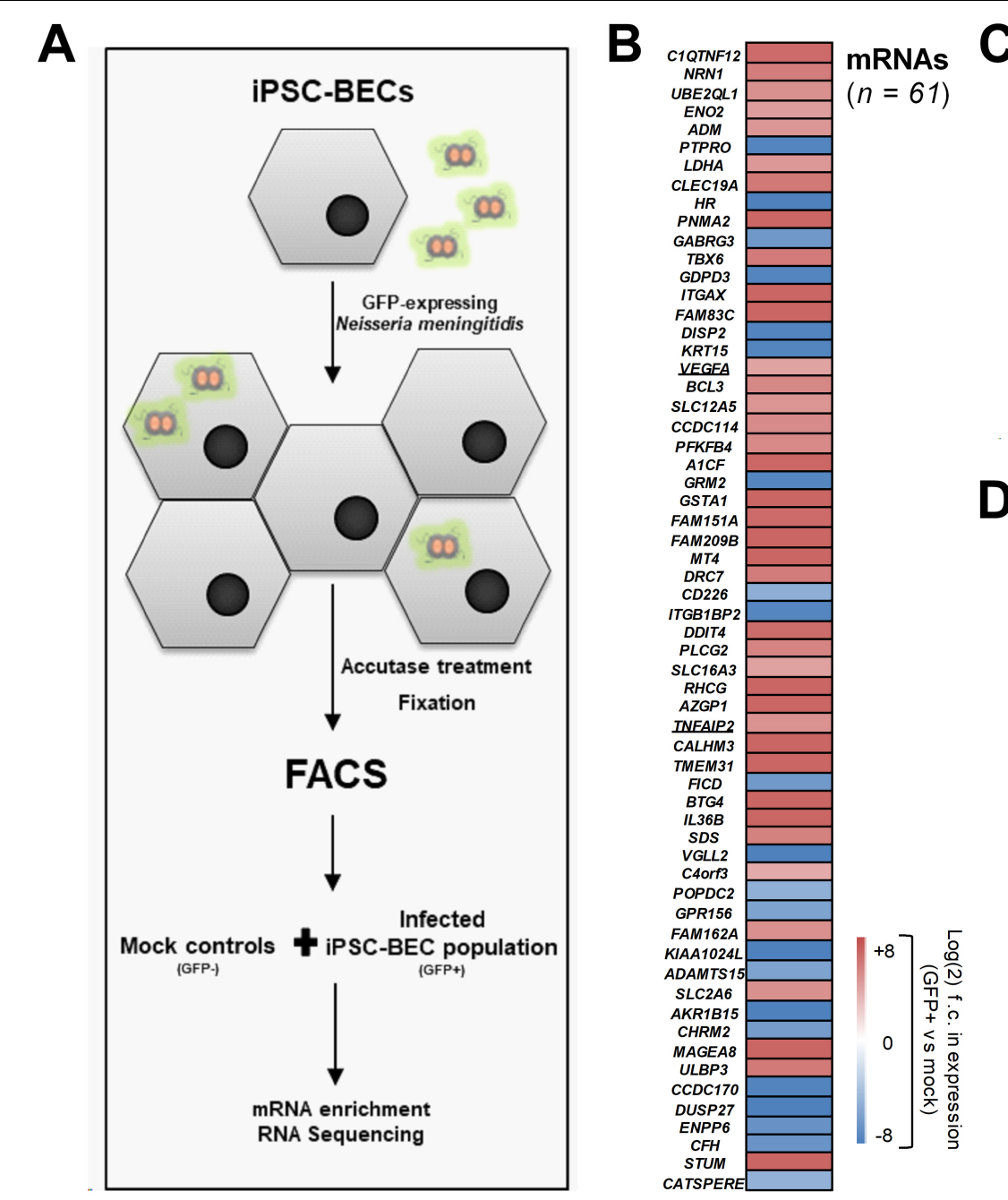

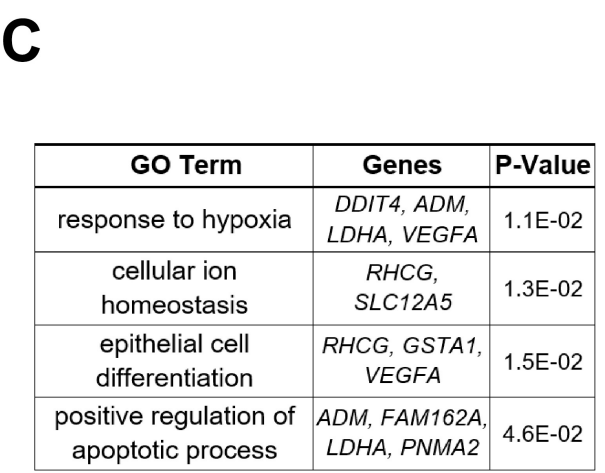

D
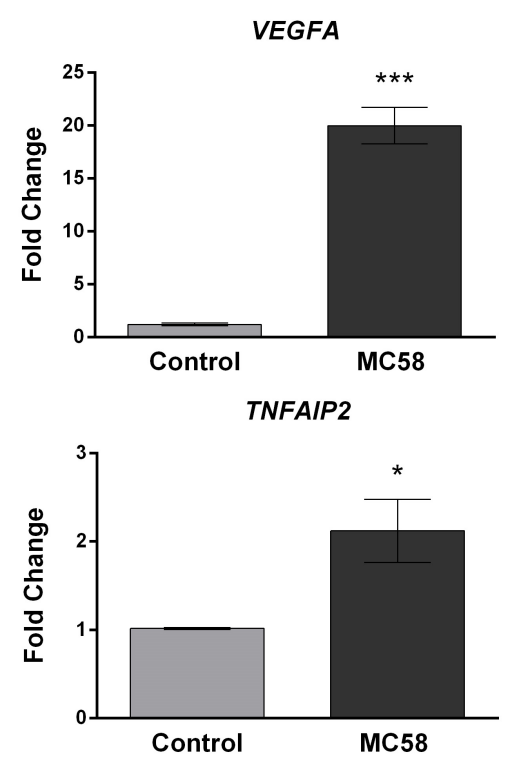

FIGURE 5 | RNA-Seq of sort-enriched, infected iPSC-BECs. (A) Experimental workflow. iPSC-BECs were infected with Nm-GFP at MOI 10, detached through Accutase treatment, and fixed in RNAlater $($. An outline of the gating strategy is provided in Supplementary Figure 5A. Mock controls without Nm challenge were sorted and collected in parallel (i.e., GFP-negative gated population P3 of mock, Supplementary Figure 5A). Total RNA was extracted from each sample and polyadenylated transcripts were converted into cDNA libraries and sequenced to $\sim 25-30$ million reads/library. (B) Heat map showing differentially expressed mRNAs between GFP-positive, infected cells and mock controls (without $\mathrm{Nm}$ challenge) at $24 \mathrm{~h}$ of infection. Plotted are all genes that were significantly differentially expressed (adjusted $P$-value < 0.1; DESeq2). Sequencing data was derived from two biological replicates. (C) Gene Ontology analysis of differentially expressed mRNAs shown in (B), acquired with DAVID bioinformatics resources. Enriched GO terms with $P$-value $<0.05$ are shown as well as the differentially expressed mRNAs corresponding to the respective pathway. (D) Validation of RNA-Seq data by qPCR. VEGFA and TNFAIP2 mRNA levels were increased at 24 h after MC58 infection (MOI 10) as compared to mock-treated cultures. RNA was isolated from monolayers of iPSC-BECs without sorting. The data are presented as mean \pm S.E.M of three independent experiments done in triplicate. Student's $t$-test was used to determine significance. ${ }^{*} p<0.05$; ${ }^{* * *} p<0.001$.

growth factor A (VEGFA), which was previously implicated as a target of meningitic Escherichia coli to disrupt the BBB (Yang et al., 2016), was upregulated by invaded iPSCBECs, as judged from RNA-Seq (23-fold vs. mock). This strong induction could be confirmed by qPCR (Figure 5D). Likewise, induced expression of TNFAIP2 mRNA, encoding the proinflammatory $\mathrm{TNF} \alpha$-induced protein 2 known to be involved in the response to $\mathrm{Nm}$ infection (Linhartova et al., 2006; Borkowski et al., 2014), was observed by both RNA-Seq and qPCR (Figures 5B,D). Together, this global expression dataset confirms previous observations, but may also serve as a valuable resource for future studies.

\section{DISCUSSION}

Knowledge of the interaction between $\mathrm{Nm}$ and BECs is critical for understanding meningococcal meningitis progression and for the development of novel therapeutic intervention. Until now, modeling this interaction has proved difficult due to the intrinsic properties of BECs and the human-exclusive tropism of $\mathrm{Nm}$. In vitro studies of $\mathrm{Nm}$ interaction with brain capillaries have largely relied on human bone marrow-derived endothelial cells (Hoffmann et al., 2001; Bernard et al., 2014) and immortalized cell lines such as the brain microvascular endothelial cell line hCMEC/D3 (Weksler et al., 2005; Coureuil et al., 2009, 2010; 
Bernard et al., 2014) and HBMECs (Unkmeir et al., 2002; Nikulin et al., 2006). While HBMECs lack Claudin-5 expression, hCMEC/D3 cells express Claudin-5 but lack continuous Occludin and exhibit relatively low TEER (Weksler et al., 2005; Eigenmann et al., 2013). Alternatively, humanized mice have been used in vivo, but these must rely on known interactions and/or have limited translatability (Johswich et al., 2013; Melican et al., 2014). Here, we demonstrate a significant technical advance in the modeling of $\mathrm{Nm}$ interaction with human BECs by using iPSC-BECs. This model overcomes drawbacks of current models, as (i) it is of human origin while still being highly scalable, and (ii) it retains important BEC properties, such as the expression of tight junction complexes that translate into high barrier potential. Moreover, this model has been used to model the BBB in the past. However, here we propose to model the BECs of the meningeal b-CSF barrier. BECs that constitute the capillaries located within the subarachnoid space possess high barrier properties and maintain BEC phenotypes, without the support of neurovascular unit cell types such as pericytes and astrocytes (Cassella et al., 1997; Møllgård et al., 2017; Rua and McGavern, 2018; Weller et al., 2018). Our data suggest that the iPSC-BEC model can be used to study $\mathrm{Nm}$ attachment, invasion, disruption of tight junctions and endothelial barrier, immune activation as well as transcriptome changes upon infection. Moreover, our results correlate well with previous work regarding invasion of several $\mathrm{Nm}$ strains and mutants to immortalized cell lines, and our model expresses the identified pilus receptor, CD147, which localizes with meningococcal colonies (Figure 1E).

As a cellular model for studying central nervous system pathogens, iPSC-BECs have recently been utilized for the study of Zika virus and Group B Streptococcus infection (Kim et al., 2017; Alimonti et al., 2018). Here we used a retinoic acid enhanced iPSC-BEC model that achieves physiological TEERs that allowed us to observe that prolonged $\mathrm{Nm}$ infection leads to significant decreases in BEC TEER, and increased paracellular permeability to the small molecule sodium fluorescein and to $\mathrm{Nm}$ (Figures 2, 3D). At the tight junction level, these modifications of barrier functionality were associated with the formation of highly frayed junctions, junctional discontinuity, and opening of gaps between cells. The generation of gaps between $\mathrm{Nm}$-infected cells and subsequent opening of the paracellular route has been suggested to contribute to $\mathrm{Nm}$ crossing of BECs (Coureuil et al., 2009). Importantly, our data correlate bacterial transmigration with tight junction disruption (Figures $3 \mathbf{D}, \mathbf{A}$ ), supporting the hypothesis that $\mathrm{Nm}$ may utilize the paracellular route for BEC crossing. Although transcellular crossing at early time points of infection may occur, the observed CFU values were below the detection limit of the technique.

A particular strength of our model is the expression and localization of tight junction components, in particular Claudin5 (Helms et al., 2015; Greene et al., 2019). Here we show for the first time disruption of Claudin-5 upon $\mathrm{Nm}$ challenge (Figure 3A). Our results also support previous observations that $\mathrm{Nm}$ induces cleavage of Occludin leading to the generation of a $50-\mathrm{kDa}$ fragment detected by Western blotting (SchubertUnkmeir et al., 2010; Supplementary Figure 3C). In agreement with the mentioned observations of tight junction disruption,
$\mathrm{Nm}$ infection of iPSC-BECs upregulated host SNAI1 (Snail-1), a transcriptional repressor of tight junction components operating in the infection mechanisms of Group B Streptococcus (Kim et al., 2015, 2017). Yang et al., 2016 also correlated Snail-1 expression with the upregulation of VEGFA upon in vivo and in vitro E. coli $\mathrm{K} 1$ challenge, causing increased BBB permeability. In the present study, our RNA-Seq data showed upregulation of VEGFA in response to $\mathrm{Nm}$ infection, which was confirmed by qPCR (Figures 5B,D). Thus, the role of VEGFA in host responses to $\mathrm{Nm}$ may include bacterial hijacking mechanisms for BEC disruption, which may be worth further investigation.

Bacterial meningitis progression is characterized by the recruitment of highly activated leukocytes into the CSF, which is presumed to be triggered by the inflammatory activation of BECs (Tunkel and Scheld, 1993). Using iPSC-BECs we were able to detect RANTES and IFN- $\gamma$ secretion upon meningococcal infection, both previously detected in the CSF of patients suffering from bacterial meningitidis (Glimåker et al., 1994; Pashenkov et al., 2002). In addition, our data indicate that iPSCBECs respond to $N m$ infection by upregulating IL6 (IL-6), CXCL8 (IL-8), CXCL1 (Gro- $\alpha$ ), CXCL2 (Gro- $\beta$ ), and CCL20 (MIP3A) at the mRNA level (Figure 4B). Interestingly, the observed transcriptional upregulation did not accompany secretion of IL6 , and of IL-8 at physiological levels. Our data support published findings regarding the modeling of Group B Streptococcus infection using a similar model of iPSC-BECs that reported transcriptional evidence for immune activation (Kim et al., 2017). Taken together, we observe activation of iPSC-BECs through the transcriptional upregulation of chemokines and cytokines in addition to the detection of IFN- $\gamma$ and RANTES in the supernatant, however, further investigation may be needed to understand the regulation of cytokine secretion in this model.

Finally, RNA-Seq of sorted-enriched, infected iPSC-BECs was established to track transcriptomic changes in the host upon $\mathrm{Nm}$ internalization. For this, we built upon a fixation and FACS protocol previously established for a Salmonella-based infection system (Westermann et al., 2016). To our knowledge, this is the first time that RNA-Seq has been implemented to the study of $\mathrm{Nm}$-BEC interactions. GO term analysis of the resulting data suggested that $\mathrm{Nm}$ infection elicits hypoxia, cellular ion homeostasis and apoptotic responses in iPSC-BECs. Activation of hypoxia-inducible factor 1 (HIF1) is a well-known cell response to hypoxic conditions induced by sepsis and LPS stimulation (Peyssonnaux et al., 2007; Werth et al., 2010; Textoris et al., 2012) and HIF1 signaling was proposed to mediate VEGFA induction during Clostridium difficile infection (Huang et al., 2019). Although the impact of hypoxia and oxidative stress during $\mathrm{Nm}$ infection in particular has been poorly described, evidence of $\mathrm{Nm}$-induced oxidative DNA damage in infected cells has been previously observed (Oosthuysen et al., 2016). By contrast, positive regulation of apoptosis is a well-known transcriptomic host response to $\mathrm{Nm}$ infection (Constantin et al., 2002; Schubert-Unkmeir et al., 2007).

Notably, analysis of individual genes upregulated in the gene set revealed a few genes that have been associated to $\mathrm{Nm}$ infection but poorly explored thus far. In particular, Integrin Subunit Alpha $X$ (ITGAX) encoding for CD18/CD11c, is upregulated 
by 76 -fold (Figure 5B). CD18/CD11c has been described to be expressed in human umbilical vein endothelial cells (Langeggen et al., 2002) and to function as a phagocytic receptor for $\mathrm{Nm}$ when transfected into CHO cells (Jones et al., 2008). TNFAIP2, upregulated 33-fold (Figure 5B), is phosphorylated upon LPS stimulation (Chevrier et al., 2011) and its expression is linked to increased mortality in patients experiencing septic shock (Thair et al., 2016). Finally, $C F H$ coding for complement factor $\mathrm{H}$, a key immune regulator of the host immune response that is hijacked by $\mathrm{Nm}$ through binding to factor $\mathrm{H}$-binding protein (fBHP) (Welsch and Ram, 2008), is downregulated in host iPSC-BECs (Figure 5B). Overall, our transcriptomic analysis of specifically infected iPSC-BECs seems to be useful at late time points of infection for the detection of potential key host genes regulated in response to $\mathrm{Nm}$. Still, host transcriptomic responses to $\mathrm{Nm}$ infection are likely to be time-dependent and may vary considerably from early to late infection stages. The low infection rate at early time points (Supplementary Figure 5A) and current sensitivity of bulk RNA-Seq technologies impeded similar transcriptomics at the 4 and $8 \mathrm{~h}$ time point. However, ongoing progress in (single-cell) RNA-Seq techniques (Saliba et al., 2014) should allow for transcriptome profiling during earlier stages of $\mathrm{Nm}$ infection in future efforts. Likewise, future studies should be directed toward a more comprehensive transcriptome profiling of our infection model, wherein not only host expression changes during infection, but also that of intracellular Neisseria may be measured [(a so-called "dual RNA-Seq" approach see Westermann et al. (2012)].

Our study demonstrates that iPSC-BECs are a potentially superior model to study BEC-Nm interaction. We observed that $\mathrm{Nm}$ infection disrupts barrier properties and results in the destruction of the major BEC tight junction components, previously unable to be measured due to lack of expression/localization in previous models. This destruction greatly increases bacterial transmigration through iPSC-BEC monolayers.

\section{MATERIALS AND METHODS}

\section{Bacterial Strains and Cell Lines Used}

Neisseria meningitidis strain MC58 was used unless otherwise specified. MC58 serogroup (Sg) B strain, sequence type (ST)-74 [ST-32 clonal complex (cc)], kindly provided by E. R. Moxon (McGuinness et al., 1991). Nm serogroup C strain 8013/clone12 [SgC ST-18cc (ST-177)] (Nassif et al., 1993). Non-capsulated mutant of strain MC58 (MC58 $\Delta$ siaD) as described (Unkmeir et al., 2002). Meningococci were cultured on Columbia Agar with 5\% sheep blood (COS medium, bioMérieux, \#43049) and incubated at $37^{\circ} \mathrm{C}$ with $5 \% \mathrm{CO}_{2}$ overnight. Subsequent liquid culturing was performed in proteose-peptone medium (PPM) plus 1\% Kellogg's supplement I and II (i.e., PPM+ medium). Human iPSC cells IMR90-4 (WiCell) were maintained on Matrigel ${ }^{\circledR}$ (BD Biosciences, \#354230)-coated 6-well plates (Sarstedt) in mTeSR ${ }^{\mathrm{TM}} 1$ medium (STEMCELL Technologies, \#05850) or StemFlex medium (Gibco, \# A3349401) with daily medium changes. Passaging was performed with Versene (Gibco,
\#15040-033) or Dispase (Gibco, \#17105-041) at a splitting ratio of 1:6 or 1:12. All as described in Stebbins et al. (2016).

\section{Generation of iPSC-BECs From iPSCs}

IMR-90-4 iPSC cells were differentiated according to previously published methods (Lippmann et al., 2012, 2014; Stebbins et al., 2016; Appelt-Menzel et al., 2017, 2018). Briefly, single iPSC cells were disassociated with Accutase (Sigma-Aldrich, \#A6964) and cultured at a density of $0.75-1 \times 10^{4} \mathrm{iPSC} / \mathrm{cm}^{2}$ on Matrigel-coated 6-well plates or T75 flasks (Sarstedt). After 3-4 days, media was changed to Unconditioned Medium [DMEM/F-12 (Gibco, \#31330-038) + 20\% KnockOut ${ }^{\mathrm{TM}}$ Serum Replacement (Gibco, \#10828028) + 1\% MEM Non-Essential Amino Acids (Gibco, \#11140-035) + 0.5\% Glutamax (Gibco, \#3505-038) + $0.1 \mathrm{mM} \beta$-Mercaptoethanol (Sigma-Aldrich, \#M3148)] with daily medium changes for 6 days. The medium was then changed to EC medium [human Endothelial serumfree medium (hESFM, Gibco, \#11111-044) supplemented with $1 \%$ platelet-poor plasma derived bovine serum (PDS, Alfa Aesar, \#J64483AE), 20 ng/mL hbFGF (PeproTech, \#100-18B) and $10 \mu \mathrm{M}$ all-trans Retinoic Acid (Sigma-Aldrich, \#R2625)] for 2 days. BECs were then purified through seeding into collagen IV (Sigma-Aldrich, \#C5533)- and fibronectin (Sigma-Aldrich, \#F2006)-coated 48-well plates (Thermo-Nunc, \#150687), 12 well format transwells (Corning, \#3460 or \#3462) or chambered coverslip slides. The day after BEC purification, medium was changed to EC medium without RA and hbFGF. Infection experiments were done at day 10 of differentiation.

\section{Infection Assays}

The medium of confluent iPSC-BECs at day 10 of differentiation was changed to hESFM medium supplemented with 10\% Human Serum (HS, TCS biosciences, \#CR100-500), followed by infection with $\mathrm{Nm}$ strains with MOI of 10 (unless specifically noted) for the time indicated, no media change was conducted as described in Kim and Schubert-Unkmeir (2019). Bacteria grown overnight in solid culture were resuspended in $10 \mathrm{~mL} \mathrm{PPM+medium} \mathrm{and}$ incubated in a shaker at $37^{\circ} \mathrm{C}, 200 \mathrm{rpm}$ for 60 to $90 \mathrm{~min}$. Bacteria concentration was estimated by $\mathrm{OD}_{600}$ measurements. Bacteria or PPM+ medium alone (i.e., mock-infected controls) were then inoculated into differentiated iPSC-BEC monolayers. Infection was carried out at $37^{\circ} \mathrm{C}$ and $5 \% \mathrm{CO}_{2}$ to a maximum of $32 \mathrm{~h}$.

\section{Immunofluorescence and Microscopy}

iPSC-BEC monolayers seeded onto 8-well ibidi $\mu$-Slides (Ibidi, \#80821) were washed with PBS and fixed with methanol or $3.7 \%$ PFA for $15 \mathrm{~min}$. After washing, PFA-fixed cells were permeabilized with $0.1 \%$ Triton X-100 in PBS for $15 \mathrm{~min}$. Washing was followed by blocking in 10\% Fetal Calf Serum (Life Technologies, \#10270) or 10\% Goat Serum (Sigma-Aldrich, \#G9023) in PBS for $1 \mathrm{~h}$ at RT. Primary antibodies [ZO-1 (1:100, Proteintech, \#21773-1-AP), Claudin-5 (1:100, Abcam, \#ab15106), Occludin (1:200, Thermo, \#33-1500), and CD147 (1:100, Biorad, \#MCA2882Z)] were incubated overnight at $4^{\circ} \mathrm{C}$. After washing, incubation with secondary antibodies [Alexa 555conjugated donkey anti-rabbit (Thermo, \#A31572), Alexa 647conjugated donkey anti-mouse (Thermo, \#A31571) or Alexa 
488-conjugated goat anti-mouse (Thermo, \#A11001)] was done at room temperature for $1 \mathrm{~h}$. Confocal microscopy images were acquired with a Zeiss LSM 780 microscope. ZEN software (version 2.3 blue edition) was used for image analysis.

\section{TEER Measurements, Paracellular Permeability Studies, and Bacterial Transmigration Assays}

At day 10 of differentiation the electrical resistance of iPSC-BECs was measured using a Millicell ERS-2 instrument (Merck) as previously described (Stebbins et al., 2016). Infected or control transwells were used to measure TEER every $2 \mathrm{~h}$ and to estimate sodium fluorescein $(\mathrm{NaF})$ permeability at 24 and $32 \mathrm{~h}$ p.i., as described (Stebbins et al., 2016). Transwells with pore size of $3 \mu \mathrm{m}$ were used for bacterial transmigration studies. Briefly, at each mentioned time point, transwells were washed with PBS and moved to fresh EC medium for $30 \mathrm{~min}$, after which $100 \mu \mathrm{L}$ of basolateral medium were plated into 5\% sheep blood agar plates for counting of colonies [method adapted from Coureuil et al. (2009)]. Limit of detection was determined by multiplying the minimum CFU possible to be measured on agar plates (15 CFU per $1.5 \mathrm{~mL}$ of basolateral medium) by the minimum CFU number recommended for usage in spread plate protocols for CFU enumeration by the American Society for Microbiology (Wise, 2006).

\section{Protein Collection and Western Blotting}

iPSC-BEC monolayers were washed with ice-cold PBS three times, then total protein lysates were collected with lysis buffer [10 mM Tris-HCL pH 6.8, $100 \mathrm{mM} \mathrm{NaCl,} 1 \mathrm{mM}$ EDTA, $10 \%$ Glycerol, $1 \%$ Triton $^{\mathrm{TM}} \mathrm{X}-100,0.1 \%$ SDS, $0.5 \%$ sodium deoxycholate, $2 \mathrm{mM} \mathrm{Na}_{3} \mathrm{VO}_{4}, 50 \mathrm{mM}$ Sodium Fluoride, $50 \mu \mathrm{g} / \mathrm{ml}$ Pefabloc (Carl Roth, \#A154) and protease inhibitors (Roche, \# 4693116001)]. After resuspension and incubation for $30 \mathrm{~min}$ on ice, lysates were centrifuged for $20 \mathrm{~min}$ at $12,000 \mathrm{~g}$ at $4^{\circ} \mathrm{C}$. Total protein concentration was estimated using the Pierce BCA Protein Kit Assay (Thermo, \# 23225) and 10 to $25 \mu \mathrm{g}$ of protein were electrophoretically separated using 6 or $12 \%$ acrylamide gels. Following protein transfer to nitrocellulose membranes (GE Healthcare Life Sciences, \# 10600001), blocking was performed with $5 \%$ skim milk with $0.1 \%$ Tween 20 in PBS solution for $1 \mathrm{~h}$. Primary antibody incubation [Occludin (1:500), ZO-1 (1:1000), Claudin-5 (1:250), $\beta$-Actin (1:1000, Cell Signaling, \#4967)] occurred overnight at $4^{\circ} \mathrm{C}$. The following day, membranes were washed and incubated for at least $1 \mathrm{~h}$ with secondary antibody 1:10,000 Peroxidase AffiniPure Goat AntiMouse (Jackson ImmunoResearch, \#115-035-044) or 1:5,000 Anti-Rabbit (Jackson ImmunoResearch, \#115-035-006) at room temperature. Detected proteins were visualized using the Clarity Western ECL kit (Biorad, \#170-5060).

\section{RNA Isolation and Quantitative PCR}

iPSC-BEC monolayers were lysed with RNA lysis buffer and total RNA was recovered using the NucleoSpin kit (MachereyNagel, \#740955). $500 \mathrm{ng}$ of total RNA was used to synthetize cDNA with SuperScript ${ }^{\text {TM }}$ IV VILO ${ }^{\mathrm{TM}}$ (Invitrogen, \#11756050) and quantitative PCR data was collected with a StepOnePlus real-time PCR thermocycler (Thermo). Quantitative PCR for CXCL1, CXCL2, CXCL8, CCL20, IL6, SNAI1 mRNAs and $18 S$ rRNA was performed using PowerUp SYBR Green (Thermo, \#A25741) and primers formerly described (van Sorge et al., 2008; Rho et al., 2010), while TaqMan (Thermo, \#4369016) was used for detection of TJP1 (ZO-1; Hs0155186_m1), CLDN5 (Claudin5; Hs00533949_s1), OCLN (Occludin; Hs00170162_m1), CCL5 (RANTES; Hs00982282_m1), IFNG (IFN- $\gamma$; Hs00989291_m1), VEGFA (Hs00900055_m1), TNFAIP2 (Hs00969305_m1), and 18S (Hs99999901_s1). Data are presented as fold change over 18S using the cycle threshold $(\Delta \Delta \mathrm{CT})$ calculation.

\section{Cytokine/Chemokine Multiplex Bead Assays}

Supernatants of iPSC-BEC monolayers of mock controls or cells infected with MC58, MC58 $\Delta$ siaD or $8013 / 12$ at 2, 4, 6, 8, and $24 \mathrm{~h}$ p.i were collected and tested for IL-1 $\beta$, IL-6, IL-8, GMCSF, Gro- $\alpha$, Gro- $\beta$, TNF- $\alpha$, IFN- $\gamma$, VCAM-1, ICAM-1, E-selectin, vWF-A2, MCP-1 and RANTES presence using a customized anti-human cytokine Luminex Multiplex Assay (R\&D Systems), according to the manufacturer's instructions. Baseline levels of all targets present in infection medium alone (hESFM supplemented with $10 \%$ HS) were subtracted from sample measurements for data analysis.

\section{FACS, RNA Extraction and DNase Treatment}

Infection was carried out with GFP-expressing MC58 and mockinfected controls for $24 \mathrm{~h}$ p.i. for two independent experiments in iPSC-BEC monolayers previously seeded onto 6-well plates in hESFM $+10 \%$ HS. Cells were dissociated using Accutase for at least $20 \mathrm{~min}$ at $37^{\circ} \mathrm{C}$ and detached cells were centrifuged at $1200 \mathrm{rpm}$ for $5 \mathrm{~min}$. Cells were resuspended in RNAlater solution (Qiagen, \#76104) supplemented with $200 \mu \mathrm{g} / \mathrm{mL}$ gentamicin and stored at $4^{\circ} \mathrm{C}$ until the sorting day. Cells were pelleted (250 g, $5 \mathrm{~min}$ at RT) and resuspended in 300 to $1500 \mu \mathrm{L}$ of ice-cold PBS for sorting. Cells were analyzed and sorted into GFP-negative and GFP-positive sub-populations using a FACSAria III device (BD Biosciences) at $4^{\circ} \mathrm{C}$ and using a 100 micron nozzle, as previously described (Westermann et al., 2016). Fractioned cells were lysed by resuspension in TRIzol (Invitrogen, \#15596026) and RNA was precipitated through the TRIzol method. Briefly, resuspended cells and chloroform $(0.2 \mathrm{~mL} / \mathrm{mL})$ were added to 5PRIME Phase Lock Gel Heavy tubes (Quantabio, \#733-2478). The tubes were spun at $12,000 \times \mathrm{g}$ for $15 \mathrm{~min}$ at $4^{\circ} \mathrm{C}$. Isopropanol (1 volume) and GlycoBlue (Ambion, \#AM9516) were added to the obtained aqueous phase and the mixture was incubated at $-20^{\circ} \mathrm{C}$ overnight. The mixture was then spun for $30 \mathrm{~min}$ at full speed and the pellet was rinsed with cold 70-75\% ethanol. After air-drying for $10 \mathrm{~min}$, the pellet was dissolved in RNasefree water by $5 \mathrm{~min}$ of incubation at $65^{\circ} \mathrm{C}$ and $850 \mathrm{rpm}$ on a thermoshaker (Eppendorf). DNase I digestion (Fermentas) was carried out according to the manufacturer's instructions. Total RNA was precipitated by phenol-chloroform extraction followed 
by ethanol precipitation. Briefly, 2.5 volumes of 30:1 RNA precipitation mix (EtOH: $3 \mathrm{M} \mathrm{NaOAC}, \mathrm{pH}$ 6.5) and Glycoblue were added to the aqueous fraction containing DNA-depleted RNA and precipitation was performed as described above.

\section{mRNA Enrichment, cDNA Library Generation and RNA-Seq}

From the total RNA preparations, first-strand cDNA was synthesized using an oligo $(\mathrm{dT})_{25}$ primer. After fragmentation, the Illumina TruSeq sequencing adapters were ligated in a strandspecific manner to the $5^{\prime}$ and $3^{\prime}$ ends of the cDNA fragments. The cDNA was amplified by PCR using a proofreading enzyme. The primers used for PCR amplification were designed for TruSeq sequencing according to the instructions of Illumina (the combined length of the flanking sequences was 136 bases). The final cDNA samples were analyzed on a Shimadzu MultiNA microchip electrophoresis system. For Illumina sequencing, cDNA libraries samples were pooled in equimolar amounts. The cDNA pools were size fractionated in the size range of 200-600 bp using a differential clean-up with the Agencourt AMPure kit. An aliquot of the size-fractionated cDNA pool was analyzed by capillary electrophoresis. Sequencing was performed on a NextSeq500 platform (Illumina) in single-end mode, for 75 cycles.

\section{Computational Analysis of RNA-Seq Data}

Illumina reads were initially quality trimmed with a Phred quality score cut-off of 20 and afterward the adapter sequences were removed. Both trimming steps were done by cutadapt version 1.17 (Martin, 2011). For the poly(A) trimming, size filtering, and mapping, the RNA-Seq analysis tool READemption version 0.4.3 (Förstner et al., 2014) was used, which integrates the short read mapper segemehl (Hoffmann et al., 2009). Before mapping, poly $(\mathrm{A})$ sequences were clipped from the reads. Afterward, all reads that had a length shorter than 20 nucleotides were discarded. The remaining reads were mapped, using segemehl's split align feature, to the genomes of $\mathrm{Nm}$ MC58 (NCBI RefSeq accession number: NC_003112.2; as an additional quality control) and human (GENCODE release 28: GRCh38.p12). Reads with an accuracy equal or greater than 95\% were kept for further analysis. Segemehl's realigner lack (Otto et al., 2014) was used for remapping reads that previously could not be mapped due to multiple splice events. For the human-mapped reads, gene quantification was carried out by READemption (Förstner et al., 2014), while differential gene expression analysis was performed using DESeq2 version 1.20.0 (Love et al., 2014). Coverage files in wiggle (WIG) format were produced by READemption in a strand-specific manner, and normalized by the total number of aligned reads per organism multiplied by 1 million.

\section{Statistics}

GraphPad Prism (Version 6.01) was used for statistical significance, for which a $P$-value of less than 0.05 was accepted.
Student's $t$-test was used for two-group comparisons. ANOVA was used for three-group comparisons.

\section{DATA AVAILABILITY}

The RNA-Seq data discussed in this publication have been deposited in NCBI's Gene Expression Omnibus (PMID: 11752295) and are accessible through GEO Series accession number GSE126449. Publicly available datasets were analyzed in this study. This data can be found here: https://www.ncbi.nlm. nih.gov/geo/query/acc.cgi?acc=GSE126449.

\section{AUTHOR CONTRIBUTIONS}

SMG, BK, AA-M, and AS-U contributed to the conception and design of the study. SMG performed the experiments and wrote the manuscript. SMG and BK designed the experiments and analyzed the data. TS, KF, and AW analyzed the RNA-Seq data. AS-U acquired funding. ES, BK, AA-M, MM, KO, TH, and AS-U provided reagents and/or resources. BK, MM, AA-M, and AS-U supervised the work. All authors contributed to the manuscript revision, and read and approved the submitted version.

\section{FUNDING}

This publication was funded by the German Research Foundation (DFG) and the University of Würzburg in the funding programme Open Access Publishing. SMG was supported by Research Training Group "3D Tissue Models for Studying Microbial Infections by Human Pathogens" (RTG 2157). Grant of the DFG was awarded to AS-U. BK was supported by a Postdoctoral Fellowship from the Alexander von Humboldt Foundation. National Institutes of Health grant NS103844 awarded to ES. MM and AA-M were supported by public funding from the German Ministry for Education and Research BMBF (HiPSTAR, funding code: FKZ 01EK1608A) and the SET Foundation (Stiftung zur Förderung der Erforschung von Ersatz- und Ergänzungsmethoden zur Einschränkung von Tierversuchen, project 60).

\section{ACKNOWLEDGMENTS}

We thank Dr. Nora Müller for her help with confocal microscopy.

\section{SUPPLEMENTARY MATERIAL}

The Supplementary Material for this article can be found online at: https://www.frontiersin.org/articles/10.3389/fmicb. 2019.01181/full\#supplementary-material 


\section{REFERENCES}

Alimonti, J. B., Ribecco-Lutkiewicz, M., Sodja, C., Jezierski, A., Stanimirovic, D. B., Liu, Q., et al. (2018). Zika virus crosses an in vitro human blood brain barrier model. Fluids Barriers CNS 15:15. doi: 10.1186/s12987-018-0100-y

Appelt-Menzel, A., Cubukova, A., Günther, K., Edenhofer, F., Piontek, J., Krause, G., et al. (2017). Establishment of a human blood-brain barrier co-culture model mimicking the neurovascular unit using induced pluri- and multipotent stem cells. Stem Cell Rep. 8, 894-906. doi: 10.1016/j.stemcr.2017.02.021

Appelt-Menzel, A., Cubukova, A., and Metzger, M. (2018). Establishment of a human blood-brain barrier co-culture model mimicking the neurovascular unit using induced pluripotent stem cells. Curr. Protoc. Stem Cell Biol. 47:e62. doi: $10.1002 /$ cpsc. 62

Bernard, S. C., Simpson, N., Join-Lambert, O., Federici, C., Laran-Chich, M. P., Maïssa, N., et al. (2014). Pathogenic Neisseria meningitidis utilizes CD147 for vascular colonization. Nat. Med. 20, 725-731. doi: 10.1038/nm.3563

Borkowski, J., Li, L., Steinmann, U., Quednau, N., Stump-Guthier, C., Weiss, C., et al. (2014). Neisseria meningitidis elicits a pro-inflammatory response involving $\mathrm{I} \kappa \mathrm{B} \zeta$ in a human blood-cerebrospinal fluid barrier model. J. Neuroinflammation 11:163. doi: 10.1186/s12974-014-0163-x

Canfield, S. G., Stebbins, M. J., Morales, B. S., Asai, S. W., Vatine, G. D., Svendsen, C. N., et al. (2017). An isogenic blood-brain barrier model comprising brain endothelial cells, astrocytes, and neurons derived from human induced pluripotent stem cells. J. Neurochem. 140, 874-888. doi: 10.1111/jnc.13923

Cassella, J. P., Lawrenson, J. G., and Firth, J. A. (1997). Development of endothelial paracellular clefts and their tight junctions in the pial microvessels of the rat. J. Neurocytol. 26, 567-575. doi: 10.1023/A:1015438624949

Chevrier, N., Mertins, P., Artyomov, M. N., Shalek, A. K., Iannacone, M., Ciaccio, M. F., et al. (2011). Systematic discovery of TLR signaling components delineates viral-sensing circuits. Cell 147, 853-867. doi: 10.1016/j.cell.2011. 10.022

Constantin, D., Ala'Aldeen, D., and Murphy, S. (2002). Transcriptional activation of nitric oxide synthase-2, and NO-induced cell death, in mouse cerebrovascular endothelium exposed to Neisseria meningitidis. J. Neurochem. 81, 270-276. doi: 10.1046/j.1471-4159.2002.00816.x

Coureuil, M., Join-Lambert, O., Lécuyer, H., Bourdoulous, S., Marullo, S., and Nassif, X. (2012). Mechanism of meningeal invasion by Neisseria meningitidis. Virulence 3, 164-172. doi: 10.4161/viru.18639

Coureuil, M., Lécuyer, H., Scott, M. G. H., Boularan, C., Enslen, H., Soyer, M., et al. (2010). Meningococcus hijacks a $\beta 2$-adrenoceptor/ $\beta$-arrestin pathway to cross brain microvasculature endothelium. Cell 143, 1149-1160. doi: 10.1016/j.cell. 2010.11.035

Coureuil, M., Mikaty, G., Miller, F., Lécuyer, H., Bernard, C., Bourdoulous, S., et al. (2009). Meningococcal type IV pili recruit the polarity complex to cross the brain endothelium. Science 325, 83-87. doi: 10.1126/science.1173196

Dick, J., Hebling, S., Becam, J., Taha, M.-K., and Schubert-Unkmeir, A. (2017). Comparison of the inflammatory response of brain microvascular and peripheral endothelial cells following infection with Neisseria meningitidis. Pathog. Dis. 75:ftx038. doi: 10.1093/femspd/ftx038

Eigenmann, D. E., Xue, G., Kim, K. S., Moses, A. V., Hamburger, M., and Oufir, M. (2013). Comparative study of four immortalized human brain capillary endothelial cell lines, hCMEC/D3, hBMEC, TY10, and BB19, and optimization of culture conditions, for an in vitro blood-brain barrier model for drug permeability studies. Fluids Barriers CNS 10:33. doi: 10.1186/2045-8118-10-33

Engelhardt, B., and Sorokin, L. (2009). The blood-brain and the bloodcerebrospinal fluid barriers: function and dysfunction. Semin. Immunopathol. 31, 497-511. doi: 10.1007/s00281-009-0177-170

Förstner, K. U., Vogel, J., and Sharma, C. M. (2014). READemption - a tool for the computational analysis of deep-sequencing - based transcriptome data. Bioinformatics 30, 3421-3423. doi: 10.1093/bioinformatics/btu533

Glimåker, M., Olcén, P., and Andersson, B. (1994). Interferon- $\gamma$ in cerebrospinal fluid from patients with viral and bacterial meningitis. Scand. J. Infect. Dis. 26, 141-147. doi: 10.3109/00365549409011777

Greene, C., Hanley, N., and Campbell, M. (2019). Claudin-5: gatekeeper of neurological function. Fluids Barriers CNS 16:3. doi: 10.1186/s12987-0190123-z

Helms, H. C., Abbott, N. J., Burek, M., Cecchelli, R., Couraud, P. O., Deli, M. A., et al. (2015). In vitro models of the blood-brain barrier: an overview of commonly used brain endothelial cell culture models and guidelines for their use. J. Cereb. Blood Flow Metab. 36, 862-890. doi: 10.1177/0271678X16630991

Hoffmann, I., Eugène, E., Nassif, X., Couraud, P. O., and Bourdoulous, S. (2001). Activation of ErbB2 receptor tyrosine kinase supports invasion of endothelial cells by Neisseria meningitidis. J. Cell Biol. 155, 133-143. doi: 10.1083/jcb. 200106148

Hoffmann, S., Otto, C., Kurtz, S., Sharma, C. M., Khaitovich, P., Vogel, J., et al. (2009). Fast mapping of short sequences with mismatches, insertions and deletions using index structures. PLoS Comput. Biol. 5:e1000502. doi: 10.1371/ journal.pcbi.1000502

Huang, D. W., Sherman, B. T., and Lempicki, R. A. (2009). Systematic and integrative analysis of large gene lists using DAVID bioinformatics resources. Nat. Protoc. 4, 44-57. doi: 10.1038/nprot.2008.211

Huang, J., Kelly, C. P., Bakirtzi, K., Villafuerte Gálvez, J. A., Lyras, D., Mileto, S. J., et al. (2019). Clostridium difficile toxins induce VEGF-A and vascular permeability to promote disease pathogenesis. Nat. Microbiol. 4, 269-279. doi: 10.1038/s41564-018-0300-x

Hung, M.-C., and Christodoulides, M. (2013). The biology of neisseria adhesins. Biology 2, 1054-1109. doi: 10.3390/biology2031054

Johswich, K. O., McCaw, S. E., Islam, E., Sintsova, A., Gu, A., Shively, J. E., et al. (2013). In vivo adaptation and persistence of Neisseria meningitidis within the nasopharyngeal mucosa. PLoS Pathog. 9:e1003509. doi: 10.1371/journal.ppat. 1003509

Jones, H. E., Strid, J., Osman, M., Uronen-Hansson, H., Dixon, G., Klein, N., et al. (2008). The role of $\beta 2$ integrins and lipopolysaccharide-binding protein in the phagocytosis of dead Neisseria meningitidis. Cell. Microbiol. 10, 1634-1645. doi: 10.1111/j.1462-5822.2008.01154.x

Kim, B. J., Bee, O. B., Mcdonagh, M. A., Stebbins, M. J., Palecek, S. P., Doran, K. S., et al. (2017). Modeling group b streptococcus and blood-brain barrier interaction by using induced pluripotent stem cell-derived brain endothelial cells. mSphere 2:e398-17. doi: 10.1128/mSphere.00398-17

Kim, B. J., Hancock, B. M., Bermudez, A., Cid, N., Del Reyes, E., Van Sorge, N. M., et al. (2015). Bacterial induction of snaill contributes to blood-brain barrier disruption. J. Clin. Invest. 125, 2473-2483. doi: 10.1172/JCI74159

Kim, B. J., and Schubert-Unkmeir, A. (2019). "in vitro models for studying the interaction of Neisseria meningitidis with human brain endothelial cells," in Methods in Molecular Biology, ed. J. M. Walker (New York, NY: Humana Press), 135-148. doi: 10.1007/978-1-4939-9202-7_10

Langeggen, H., Berge, K. E., Johnson, E., and Hetland, G. (2002). Human umbilical vein endothelial cells express complement receptor 1 (CD35) and complement receptor 4 (CD11c/ CD18) in vitro. Inflammation 26, 103-110. doi: 10.1023/A: 1015585530204

Linhartova, I., Basler, M., Ichikawa, J., Pelicic, V., Osicka, R., Lory, S., et al. (2006). Meningococcal adhesion suppresses proapoptotic gene expression and promotes expression of genes supporting early embryonic and cytoprotective signaling of human endothelial cells. FEMS Microbiol. Lett. 263, 109-118. doi: 10.1111/j.1574-6968.2006.00407.x

Lippmann, E. S., Al-Ahmad, A., Azarin, S. M., Palecek, S. P., and Shusta, E. V. (2014). A retinoic acid-enhanced, multicellular human blood-brain barrier model derived from stem cell sources. Sci. Rep. 4:4160. doi: 10.1038/srep04160

Lippmann, E. S., Azarin, S. M., Kay, J. E., Nessler, R. A., Wilson, H. K., Al-Ahmad, A., et al. (2012). Derivation of blood-brain barrier endothelial cells from human pluripotent stem cells. Nat. Biotechnol. 30, 783-791. doi: 10.1038/nbt. 2247

Love, M. I., Huber, W., and Anders, S. (2014). Moderated estimation of fold change and dispersion for RNA-seq data with DESeq2. Genome Biol. 15:550.

Mairey, E., Genovesio, A., Donnadieu, E., Bernard, C., Jaubert, F., Pinard, E., et al. (2006). Cerebral microcirculation shear stress levels determine Neisseria meningitidis attachment sites along the blood-brain barrier. J. Exp. Med. 203, 1939-1950. doi: 10.1084/jem.20060482

Maïssa, N., Covarelli, V., Janel, S., Durel, B., Simpson, N., Bernard, S. C., et al. (2017). Strength of Neisseria meningitidis binding to endothelial cells requires highly-ordered CD147/ $/ 3$-Adrenoceptor clusters assembled by alpha-Actinin4. Nat. Commun. 8:15764. doi: 10.1038/ncomms15764

Martin, M. (2011). Cutadapt removes adapter sequences from high-throughput sequencing reads. EMBnet J. 17, 10-12. doi: 10.14806/ej.17.1.200

McGuinness, B. T., Clarke, I. N., Lambden, P. R., Barlow, A. K., Heckels, J. E., Poolman, J. T., et al. (1991). Point mutation in meningococcal por a gene 
associated with increased endemic disease. Lancet 337, 514-517. doi: 10.1016/ 0140-6736(91)91297-8

Melican, K., Aubey, F., and Duménil, G. (2014). Humanized mouse model to study bacterial infections targeting the microvasculature. J. Vis. Exp. 86:51134. doi: $10.3791 / 51134$

Møllgård, K., Dziegielewska, K. M., Holst, C. B., Habgood, M. D., and Saunders, N. R. (2017). Brain barriers and functional interfaces with sequential appearance of $\mathrm{ABC}$ efflux transporters during human development. Sci. Rep. 7:11603. doi: 10.1038/s41598-017-11596-0

Nassif, X., Lowy, J., Stenberg, P., O’Gaora, P., Ganji, A., and So, M. (1993). Antigenic variation of pilin regulates adhesion of Neisseria meningitidis to human epithelial cells. Mol. Microbiol. 8, 719-725. doi: 10.1111/j.1365-2958. 1993.tb01615.x

Ni, Y., Teng, T., Li, R., Simonyi, A., Sun, G. Y., and Lee, J. C. (2017). TNF $\alpha$ alters occludin and cerebral endothelial permeability: role of p38MAPK. PLoS One 12:e0170346. doi: 10.1371/journal.pone.0170346

Nikulin, J., Panzner, U., Frosch, M., and Schubert-Unkmeir, A. (2006). Intracellular survival and replication of Neisseria meningitidis in human brain microvascular endothelial cells. Int. J. Med. Microbiol. 296, 553-558. doi: 10.1016/j.ijmm.2006. 06.006

Oosthuysen, W. F., Mueller, T., Dittrich, M. T., and Schubert-Unkmeir, A. (2016). Neisseria meningitidis causes cell cycle arrest of human brain microvascular endothelial cells at S phase via p21 and cyclin G2. Cell. Microbiol. 18, 46-65. doi: $10.1111 / \mathrm{cmi} .12482$

Otto, C., Stadler, P. F., and Hoffmann, S. (2014). Lacking alignments? The next-generation sequencing mapper segemehl revisited. Bioinformatics 30, 1837-1843. doi: 10.1093/bioinformatics/btu146

Pashenkov, M., Teleshova, N., Kouwenhoven, M., Smirnova, T., Jin, Y. P., Kostulas, V., et al. (2002). Recruitment of dendritic cells to the cerebrospinal fluid in bacterial neuroinfections. J. Neuroimmunol. 122, 106-116. doi: 10.1016/s01655728(01)00451-9

Peyssonnaux, C., Cejudo-Martin, P., Doedens, A., Zinkernagel, A. S., Johnson, R. S., and Nizet, V. (2007). Cutting edge: essential role of hypoxia inducible factor-1 in development of lipopolysaccharide-induced sepsis. J. Immunol. 178, 7516-7519. doi: 10.4049/jimmunol.178.12.7516

Quagliarello, V., and Scheld, W. (1992). Bacterial meningitis: pathogenesis, pathophysiology, and progress. N. Engl. J. Med. 327, 864-872. doi: 10.1056/ NEJM199209173271208

Rho, H. W., Lee, B. C., Choi, E. S., Choi, I. J., Lee, Y. S., and Goh, S. H. (2010). Identification of valid reference genes for gene expression studies of human stomach cancer by reverse transcription-qPCR. BMC Cancer 10:240. doi: 10 . 1186/1471-2407-10-240

Rouphael, N. G., and Stephens, D. S. (2012). Neisseria meningitidis: biology, microbiology, and epidemiology. Methods Mol Biol. 799, 1-20. doi: 10.1016/ B978-0-12-397169-2.00098-96

Rua, R., and McGavern, D. B. (2018). Advances in meningeal immunity. Trends Mol. Med. 24, 542-559. doi: 10.1016/j.molmed.2018.04.003

Saliba, A. E., Westermann, A. J., Gorski, S. A., and Vogel, J. (2014). Single-cell RNA-seq: advances and future challenges. Nucleic Acids Res. 42, 8845-8860. doi: 10.1093/nar/gku555

Schubert-Unkmeir, A. (2017). Molecular mechanisms involved in the interaction of Neisseria meningitidis with cells of the human blood-cerebrospinal fluid barrier. Pathog. Dis. 75:ftx023. doi: 10.1093/femspd/ftx023

Schubert-Unkmeir, A., Konrad, C., Slanina, H., Czapek, F., Hebling, S., and Frosch, M. (2010). Neisseria meningitidis induces brain microvascular endothelial cell detachment from the matrix and cleavage of occludin: a role for MMP-8. PLoS Pathog. 6:e1000874. doi: 10.1088/1757-899X/201/1/ 012018

Schubert-Unkmeir, A., Sokolova, O., Panzner, U., Eigenthaler, M., and Frosch, M. (2007). Gene expression pattern in human brain endothelial cells in response to Neisseria meningitidis. Infect. Immun. 75, 899-914. doi: 10.1128/iai. 01508-06

Sokolova, O., Heppel, N., Jägerhuber, R., Kim, K. S., Frosch, M., Eigenthaler, M., et al. (2004). Interaction of Neisseria meningitidis with human brain microvascular endothelial cells: role of MAP- and tyrosine kinases in invasion and inflammatory cytokine release. Cell. Microbiol. 6, 1153-1166. doi: 10.1111/ j.1462-5822.2004.00422.x
Stebbins, M. J., Wilson, H. K., Canfield, S. G., Qian, T., Palecek, S. P., and Shusta, E. V. (2016). Differentiation and characterization of human pluripotent stem cell-derived brain microvascular endothelial cells. Methods 101, 93-102. doi: 10.1016/j.ymeth.2015.10.016

Textoris, J., Beaufils, N., Quintana, G., Lassoud, A. B., Zieleskiewicz, L., Wiramus, S., et al. (2012). Hypoxia-inducible factor (HIF1 $\alpha$ ) gene expression in human shock states. Crit. Care 16:R120. doi: 10.1186/cc11414

Thair, S. A., Topchiy, E., Boyd, J. H., Cirstea, M., Wang, C., Nakada, T. A., et al. (2016). TNFAIP2 Inhibits Early TNF $\alpha$-Induced NF- $\kappa B$ signaling and decreases survival in septic shock patients. J. Innate Immun. 8, 57-66. doi: 10.1159/ 000437330

Tunkel, A. R., and Scheld, W. M. (1993). Pathogenesis and pathophysiology of bacterial meningitis. Clin. Microbiol. Rev. 6, 118-136. doi: 10.1128/CMR. 6.2.118

Unkmeir, A., Latsch, K., Dietrich, G., Wintermeyer, E., Schinke, B., Schwender, S., et al. (2002). Fibronectin mediates Opc-dependent internalization of Neisseria meningitidis in human brain microvascular endothelial cells. Mol. Microbiol. 46, 933-946. doi: 10.1046/j.1365-2958.2002.03222.x

van Sorge, N. M., and Doran, K. S. (2012). Defense at the border: the blood-brain barrier versus bacterial foreigners. Futur. Microbiol. 7, 383-394. doi: 10.2217/ fmb.12.1.Defense

van Sorge, N. M., Ebrahimi, C. M., McGillivray, S. M., Quach, D., Sabet, M., Guiney, G. D., et al. (2008). Anthrax toxins inhibit neutrophil signaling pathways in brain endothelium and contribute to the pathogenesis of meningitis. PLoS One 3:e2964. doi: 10.1371/journal.pone.0002964

Virji, M., Makepeace, K., Ferguson, D. J. P., Achtman, M., and Moxon, E. R. (1993). Meningococcal Opa and Opc proteins: their role in colonization and invasion of human epithelial and endothelial cells. Mol. Microbiol. 10, 499-510. doi: 10.1111/j.1365-2958.1993.tb00922.x

Weksler, B. B., Subileau, E. A., Perrière, N., Charneau, P., Holloway, K., Leveque, M., et al. (2005). Blood-brain barrier-specific properties of a human adult brain endothelial cell line. FASEB J. 19, 1872-1874. doi: 10.1096/fj.04-3458fje

Weller, R. O., Sharp, M. M., Christodoulides, M., Carare, R. O., and Møllgård, K. (2018). The meninges as barriers and facilitators for the movement of fluid, cells and pathogens related to the rodent and human CNS. Acta Neuropathol. 135, 363-385. doi: 10.1007/s00401-018-1809-z

Welsch, J. A., and Ram, S. (2008). Factor H and neisserial pathogenesis. Vaccine 26, 40-45. doi: 10.1016/j.vaccine.2008.11.060

Werth, N., Beerlage, C., Rosenberger, C., Yazdi, A. S., Edelmann, M., Amr, A., et al. (2010). Activation of hypoxia inducible factor 1 is a general phenomenon in infections with human pathogens. PLoS One 5:e11576. doi: 10.1371/journal. pone. 0011576

Westermann, A. J., Förstner, K. U., Amman, F., Barquist, L., Chao, Y., Schulte, L. N., et al. (2016). Dual RNA-seq unveils noncoding RNA functions in hostpathogen interactions. Nature 529, 496-501. doi: 10.1038/nature16547

Westermann, A. J., Gorski, S. A., and Vogel, J. (2012). Dual RNA-seq of pathogen and host. Nat. Rev. Microbiol. 10, 618-630. doi: 10.1038/nrmicro2852

Wise, K. (2006). Preparing spread plates protocols. Am. Soc. Microbiol. Microbe Libr. Available at: http://www.asmscience.org/content/education/ protocol/protocol.3085

Yang, R. C., Liu, W. T., Miao, L., Yang, X. P., Fu, J. Y., Dou, B. B., et al. (2016). Induction of VEGFA and Snail-1 by meningitic Escherichia coli mediates disruption of the blood-brain barrier. Oncotarget 7, 63839-63855. doi: 10. 18632/oncotarget.11696

Conflict of Interest Statement: The authors declare that the research was conducted in the absence of any commercial or financial relationships that could be construed as a potential conflict of interest.

Copyright (c) 2019 Martins Gomes, Westermann, Sauerwein, Hertlein, Förstner, Ohlsen, Metzger, Shusta, Kim, Appelt-Menzel and Schubert-Unkmeir. This is an open-access article distributed under the terms of the Creative Commons Attribution License (CC BY). The use, distribution or reproduction in other forums is permitted, provided the original author(s) and the copyright owner(s) are credited and that the original publication in this journal is cited, in accordance with accepted academic practice. No use, distribution or reproduction is permitted which does not comply with these terms. 